\title{
SELETIVIDADE DE HERBICIDAS APLICADOS EM PRÉ-EMERGÊNCIA NA CULTURA DO GIRASSOL EM SOLO DE TEXTURA ARGILOSA
}

\author{
Alexandre M. Brighenti' ${ }^{1}$ Marcelo F. Oliveira ${ }^{1}$, Dionísio L. P. Gazziero ${ }^{1}$, \\ Elemar Voll ${ }^{2}$ e José E. Pereira ${ }^{1}$
}

\footnotetext{
'Engenheiro Agrônomo, MSc, Pesquisador. Embrapa Soja. Caixa Postal 231. Londrina, PR 86001-970

${ }^{2}$ Engenheiro Agrônomo, PhD, Pesquisador. Embrapa Soja.
}

\section{SELETIVIDADE DE HERBICIDASRESUMO}

Dentre os inúmeros fatores que contribuem para a redução da produtividade da cultura do girassol, destaca-se a interferência causada pelas plantas daninhas. Estas espécies reduzem o crescimento da cultura, causam perdas na produtividade, ocorrendo reinfestações em cultivos em sucessão. Em função do número limitado de herbicidas registrados para o girassol, faz-se necessário um rígido programa de controle cultural, mecânico e químico. Dois experimentos foram conduzidos em área da Embrapa Soja, Londrina, PR, a fim de avaliar a seletividade de herbicidas aplicados em pré-emergência em solo de textura argilosa. Num dos experimentos foi utilizado o herbicida acetochlor nas doses 0, 1152, 2304, 3456 e $4608 \mathrm{~g} / \mathrm{ha}$. No outro, foi aplicado o oxyfluorfen nas doses $0,360,720,1080$ e $1440 \mathrm{~g} / \mathrm{ha}$. O herbicida acetochlor reduziu o teor de óleo e a produtividade do girassol, cultivar M 742, em doses iguais ou superiores a $2304 \mathrm{~g} / \mathrm{ha}$. O oxyfluorfen aplicado na dose $360 \mathrm{~g} / \mathrm{ha}$ foi seletivo à cultura do girassol. Em solos de textura arenosa e com baixos teores de matéria orgânica, os efeitos fitotóxicos destes produtos sobre o girassol, provavelmente, serão maiores.

Palavras-chave: controle químico, acetochlor, oxyfluorfen, Helianthus annuus, Asteraceae, plantas daninhas.

\section{ABSTRACT \\ Selectivity of pre-emergence broadleaf weed herbicides applied on clay soil in sunflower crop}

Weed control in sunflower is required to avoid poor growth, yield loss, and weed problems in crops grown after sunflower. Limited availability of sunflower herbicides requires a rigid weed control program consisting of cultural, mechanical, and chemical measures for the most profitable crop production. Two experiments were carried out at Embrapa Soja, Londrina, Parana State, Brazil, in 1998, to evaluate the selectivity of pre-emergence broadleaf weed herbicides in sunflower crop. In one of the experiment, acetochlor was used at rates of $0,1152,2304,3456$ and $4608 \mathrm{~g} / \mathrm{ha}$. In the other experiments, oxyfluorfen was applied at rates of $0,360,720,1080$ and $1440 \mathrm{~g} / \mathrm{ha}$. Acetochlor at $2304 \mathrm{~g} / \mathrm{ha}$ and at higher rates reduced oil content and sunflower yield. However, oxyfluorfen $(360 \mathrm{~g} / \mathrm{ha}$ ) was seletive to sunflower. The risk of fitotoxicity appears to be greater on low organic matter and coarse textured soils.

Key words: chemical control, acetochlor, oxyfluorfen, Asteraceae, Helianthus annuus, weeds. 


\section{INTRODUÇÃO}

A magnitude do dano que as plantas daninhas causam ao girassol chega a valores entre 20 e $50 \%$ de perda de rendimento de grãos (Chubb, 1975; Montes de Oca e Pearson, 1987; Trasmonte e Duarte, 1991). A presença destas invasoras durante as primeiras etapas do ciclo de cultivo do girassol resulta em plantas cloróticas, de menor porte, com diminuição severa de área foliar, diâmetro do caule e tamanho do capítulo (Blamey et al., 1997). Quando se analisa os componentes de rendimento, o número de aquênios por capítulo é aquele que apresenta maior redução (Bedmar, 1983). Deste modo, os herbicidas constituem numa alternativa excelente para eliminação das plantas daninhas. Entretanto, estes produtos podem causar danos à cultura, principalmente se utilizados incorretamente ou em discordância com as recomendações de aplicação.

Para que um herbicida possa ser utilizado com segurança na cultura do girassol, é de fundamental importância que o mesmo apresente tolerância superior à das plantas daninhas que se deseja controlar. Na prática, quanto maior for a diferença entre a tolerância da cultura e a da planta daninha, maior será a seletividade desse herbicida para a cultura e maior será a segurança na sua aplicação.

A disponibilidade de herbicidas seletivos e registrados para a cultura do girassol no Brasil é muito limitada. Apenas os herbicidas trifluralin, sethoxydim e alachlor são registrados para o controle de plantas daninhas nesta cultura, exigindo um rígido programa de controle cultural, mecânico e químico.

O objetivo desse trabalho foi avaliar a seletividade de herbicidas aplicados em condições de pré-emergência na cultura do girassol, em solo de textura argilosa.

\section{MATERIAL E MÉTODOS}

Dois experimentos foram conduzidos durante o período de 18 de maio a 01 de outubro de 1998 em área da Embrapa Soja, município de Londrina, PR, situado a $23^{\circ} 23^{\prime}$ de latitude

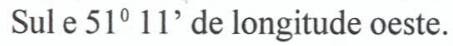

O clima da região, segundo a classificação de Köppen, pertence ao tipo $\mathrm{Cfa}$, ou seja, clima sub-tropical úmido, com chuvas em todas as estações, podendo ocorrer seca no período de inverno. A temperatura média anual está em torno de $20,7{ }^{\circ} \mathrm{C}$ e a precipitação média anual em torno de $1615 \mathrm{~mm}$ (Corrêa et al., 1982).

O solo da área onde foram conduzidos os experimentos foi classificado como Latossolo Roxo Distrófico, cujos resultados de análises física e de fertilidade encontram-se na Tabela 1.

O delineamento experimental utilizado foi de blocos casualizados, com quatro repetições. Num dos experimentos, foi utilizado o herbicida acetochlor nas doses $0,1152,2304$, $3456 \mathrm{e} 4608 \mathrm{~g} / \mathrm{ha}$. No outro, foi aplicado o oxyfluorfen nas doses $0,360,720,1080$ e $1440 \mathrm{~g} /$ ha. A cultura foi instalada utilizando-se o híbrido M 742, no espaçamento de 0,90 m, com cinco sementes por metro linear. A área das parcelas foi de 20 $\mathrm{m}^{2}$ (4 $\left.\mathrm{m} \times 5 \mathrm{~m}\right)$. A adubação de semeadura foi constituída de $350 \mathrm{~kg} / \mathrm{ha}$ de 5-25-25, distribuído a lanço em toda a área e incorporado com grade niveladora. Aos 30 dias após a semeadura (DAS), foi realizada a adubação em cobertura com $22 \mathrm{~kg}$ de nitrogênio/ha e aplicado boro, via foliar, na dose de $1,2 \mathrm{~kg} /$ ha. A aplicação dos herbicidas foi realizada após a semeadura, em pré-emergência. Utilizou-se um pulverizador costal, à pressão constante, mantida por $\mathrm{CO}_{2}$ comprimido, de $2,15 \mathrm{~kg} / \mathrm{cm}^{2}$, equipado com barra de $2,0 \mathrm{~m}$ de largura e quatro bicos de jato plano $80015-\mathrm{BD}$, distanciados de $0,5 \mathrm{~m}$, com volume de pulverização equivalente a $150 \mathrm{l} / \mathrm{ha}$. Por ocasião da aplicação dos produtos a temperatura do ambiente era de $23{ }^{\circ} \mathrm{C}$, a umidade relativa do ar era de $78 \%$, com solo úmido na superfície e velocidade do vento de $4 \mathrm{~km} / \mathrm{h}$. O experimento foi mantido sem interferência de plantas daninhas para se avaliar somente o efeito dos produtos sobre a cultura. $\mathrm{O}$ grau de fitotoxicidade foi avaliado através de escala percentual, aos 20 e 40 DAS, onde $0 \%$ correspondeu à ausência de sintomas e $100 \%$ à morte de plantas. O teor de óleo foi determinado através de ressonância magnética nuclear, com equipamento UMR, marca Oxford, modelo 400. A produtividade da cultura foi avaliada a partir da colheita de duas linhas de $4 \mathrm{~m}$ de comprimento na área central das parcelas $\left(7,2 \mathrm{~m}^{2}\right)$. Modelos de regressão foram ajustados aos dados observados, tendo como variável resposta a fitotoxicidade aos 20 e $40 \mathrm{DAS}$, o teor de óleo, a produtividade e as doses dos herbicidas como variável explanatória.

Tabela 1. Análises física e de fertilidade do solo, para a camada de 0-20 cm, da área experimental. Embrapa Soja, Londrina, PR, $1998^{1}$.

\begin{tabular}{|c|c|c|c|c|c|c|c|c|c|c|c|c|c|}
\hline Argila & Silte & Areia & MO & $\mathrm{P}$ & $\begin{array}{c}\mathrm{PH} \\
\mathrm{CaCl}_{2}\end{array}$ & $\mathrm{Al}^{+3}$ & $\mathrm{~K}$ & $\mathrm{Ca}$ & $\mathrm{Mg}$ & $\mathrm{H}^{+}+\mathrm{Al}^{+3}$ & SB & CTC & V \\
\hline -..-... & -.--- & & -.-- & $\mathrm{mg} / \mathrm{dm}^{3}$ & & -------. & 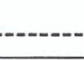 & - & $110 \mathrm{I}_{\mathrm{c}} / \mathrm{c}$ & & & --.-- & $\%$ \\
\hline 76,2 & 15,4 & 8,4 & 2,89 & 20,5 & 5,01 & 0,05 & 0,40 & 4,65 & 1,60 & 5,71 & 6,65 & 12,36 & 53,80 \\
\hline
\end{tabular}




\section{RESULTADOS E DISCUSSÃO}

O grau de fitotoxicidade em plantas de girassol apresentou aumento linear com o incremento das doses de acetochlor nas épocas avaliadas (Figura 1A). A aplicação de $2304 \mathrm{~g} / \mathrm{ha}$, dose recomendada para outras culturas, causou injúrias à parte aérea das plantas. Os sintomas de intoxicação atingiram valores de $18 \%$ aos 20 DAS, intensificando-se até
40 DAS. O valor médio observado do teor de óleo foi $36,2 \%$, quando foram aplicados $2304 \mathrm{~g} / \mathrm{ha}$, enquanto na testemunha, foi $37,4 \%$ (Figura 2A). Estudos realizados em condições de laboratório revelaram que o girassol tolerou o herbicida acetochlor em doses que variaram de 1500-2000 g/ha (Prado et al., 1993). Com relação à produtividade da cultura, o valor médio observado foi $1394 \mathrm{~kg} / \mathrm{ha}$, em função da aplicação de 2304 $\mathrm{g} / \mathrm{ha}$ e, na testemunha, este valor foi $1675 \mathrm{~kg} / \mathrm{ha}$ (Figura $3 \mathrm{~A}$ ).
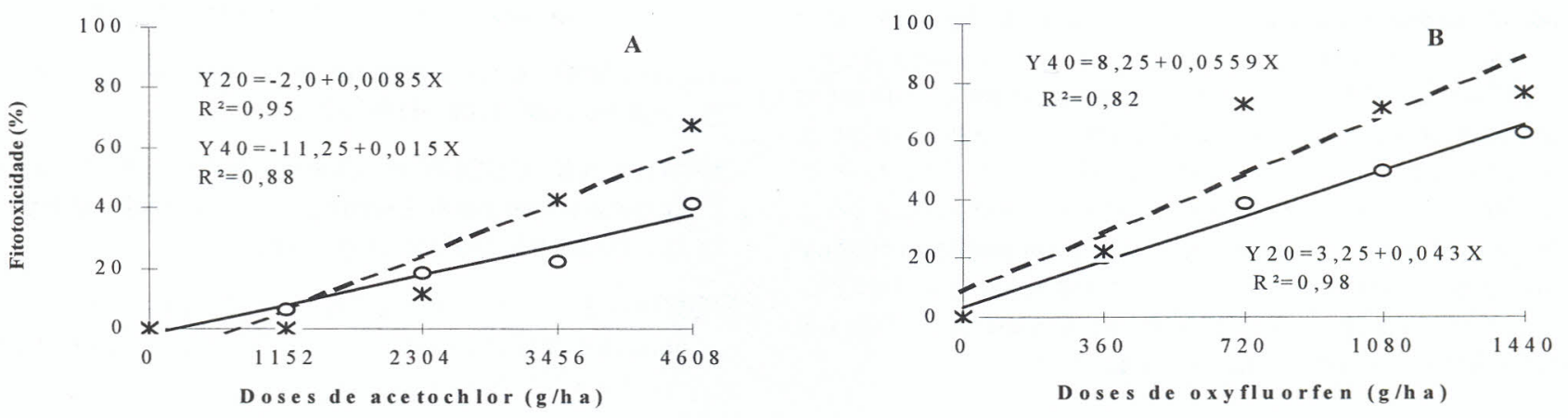

Figura 1. Fitotoxicidade de plantas de girassol aos 20 (-) e 40 (-) DAS em função das doses do herbicida acetochlor (A) e oxyfluorfen (B). Embrapa Soja, Londrina, PR, 1998.
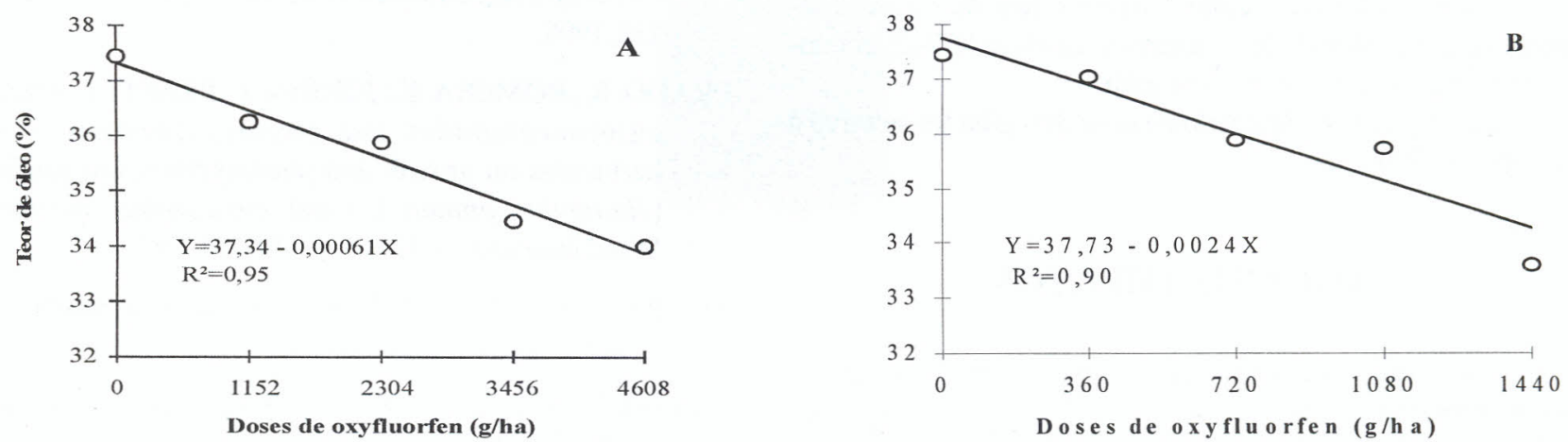

Figura 2. Teor de óleo de girassol em função das doses do herbicida acetochlor (A) e do oxyfluorfen (B). Embrapa Soja, Londrina, PR, 1998.
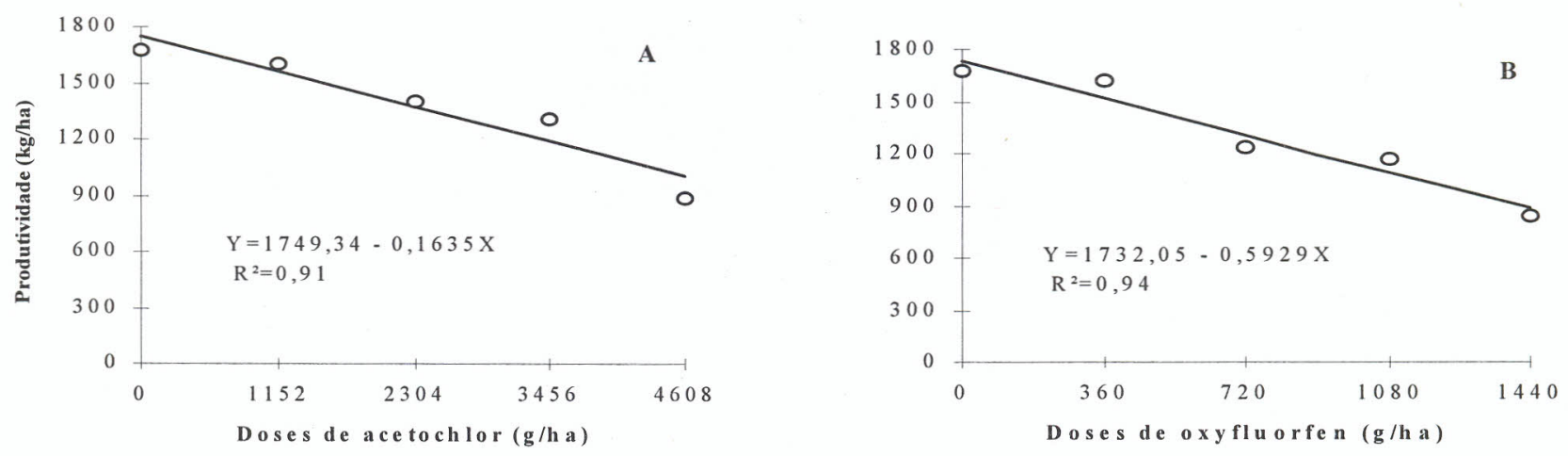

Figura 3. Produtividade da cultura do girassol em função das doses do herbicida acetochlor (A) e do oxyfluorfen (B). Embrapa Soja, Londrina, PR, 1998. 
O herbicida oxyfluorfen é recomendado em doses que variam de 240 a $1440 \mathrm{~g} / \mathrm{ha}$ para várias culturas, entre elas o arroz, o algodão, o café e o eucalipto (Rodrigues e Almeida, 1995). Este produto causou aumento nos valores de percentagem de fitotoxicidade com o aumento das doses aplicadas (Figura 1B). Foram obtidos valores em torno de $20 \%$ em função da aplicação de $360 \mathrm{~g} /$ ha aos 20 DAS e $22 \%$ aos 40 DAS. Também, os valores médios do teor de óleo e produtividade decresceram com o aumento das doses do produto (Figuras 2B e 3B). Entretanto, a aplicação de $360 \mathrm{~g} / \mathrm{ha}$ resultou em valores médios observados de $37 \%$ e $1616 \mathrm{~kg} / \mathrm{ha}$ para o teor de óleo e para a produtividade, enquanto na testemunha, foram $37,4 \%$ e $1675 \mathrm{~kg} / \mathrm{ha}$, respectivamente. Estudos realizados com esse produto na dose de $480 \mathrm{~g} /$ ha revelaram não haver redução na produtividade da cultura do girassol (Pinzariu et al.,1996). Os dois herbicidas utilizados são adsorvíveis pelos colóides do solo, tanto da argila como da matéria orgânica (Rodrigues e Almeida, 1995). Assim, em solos de textura média e arenosa e/ou com baixos teores de matéria orgânica, o efeito fitotóxico, provavelmente, será maior.

\section{CONCLUSÕES}

O herbicida acetochlor reduziu o teor de óleo das sementes e a produtividade do girassol, cultivar M 742, em doses iguais ou superiores a $2304 \mathrm{~g} / \mathrm{ha}$.

O oxyfluorfen aplicado na dose $360 \mathrm{~g} /$ ha foi seletivo à cultura do girassol.

\section{AGRADECIMENTOS}

Os autores agradecem aos colegas técnicos agrícolas da Embrapa Soja, Roberval A. Fagundes, Esmael da Silva, Mário Nakano e a Reinaldo Teruhico Moriyama pela colaboração.

\section{LITERATURA CITADA}

BEDMAR, F. Relevamiento de malezas en cultivo de girasol en el centro sudeste de la provincia de Buenos Aires. IX Reunión Argentina sobre la maleza y su control. ASAM. vol. 11: 4, p. 200-208, 1983.

BLAMEY, F.P.C.; ZOLLINGER, R.K.; SCNEITER, A.A. Sunflower production and culture. In: SCNEITER, A.A. Sunflower science and technology: Madison Wisconsin, The Amer. Soc. of Agron., Inc., p.595-670, 1997.

CHUBB, W.O. Weed competition in sunflowers. Manitoba Agron. Conf. Tech.: 119-132, 1975.

CORRÊA, A.R.; GODOY, H.; BERNARDES, L.R.M. Características climáticas de Londrina. ${ }^{2}$ ed. (Circular IAPAR 5), Londrina, PR, IAPAR, 16 p., 1982.

MONTES de OCA, C.Y.; PEARSON, F. Control de malezas anuales en el cultivo de girasol. AACREA. XII Congresso Zona Mar Y Sierras, 1987.

PINZARIU, D.; SOLONVSCHI, V.; ZBANT, M.; ZBANT, L. Research concerning some herbicide selectivity and efficiency in controlling weeds in sunflower and maize. Cercetari Agronomice in Moldova, v.29, n.1-2, p. 133138, 1996.

PRADO, R.; ROMERA, E.; JORRIN, J.; PRADO, R. Effects of chloroacetamides and phytosynthesis-inhibiting herbicides on growth and photosynthesis in sunflower (Helianthus annuus L.) and Amaranthus hybridus L. Weed Research, v.33, n.5, p.369-374, 1993.

RODRIGUES, B.N.; ALMEIDA, F.S. Guia de herbicidas. 3. ed. Londrina-PR, 1995.675 p.

TRASMONTE, D.; DUARTE, G. Control de malezas en girasol. AACREA - V Congreso Zona Oeste Arenoso, 1991. 